\title{
STUDY OF CYTOLOGICAL PATTERN IN TUBERCULAR LYMPHADENOPATHY AND ITS CORRELATION WITH ZIEHL-NEELSEN STAINING
}

\author{
Bonny Pullolil James ${ }^{1}$, Ancy Anthony Vithayathil ${ }^{2}$
}

${ }_{1}^{1}$ Assistant Professor, Department of Pulmonary Medicine, Al-Azhar Medical College.

${ }_{2}^{2}$ Assistant Professor, Department of ENT, Al-Azhar Medical College.

\section{BACKGROUND}

ABSTRACT

Tubercular lymphadenopathy is the most common form of extrapulmonary tuberculosis accounting for $50 \%$ - $65 \%$ of cases. Though confirmative evidence of tubercular lymphadenopathy is AFB culture or excisional biopsy, fine needle aspiration cytology (FNAC) is a reliable tool as it is simple, rapid and cost-effective technique and its sensitivity can be further increased by ZiehlNeelsen staining. Hence, this study was done to assess various cytological patterns in tubercular lymphadenopathy and its correlation with Ziehl-Neelsen staining.

The aim of this study is to study the various cytological patterns in tubercular lymphadenopathy and its correlation with ZiehlNeelsen staining.

\section{MATERIALS AND METHODS}

A retrospective, descriptive study was conducted in the Department of TB and Chest. Fifty two patients referred from various departments, whose FNAC patterns were suggestive of tubercular adenopathy and showed a clinical improvement after a full course of anti-tubercular treatment were included in the study. Their FNAC pattern and ZN staining were recorded. Information regarding age, gender, anatomical site, chest x-ray, Mantoux testing and comorbidities were noted. Follow-up of all patients throughout course of ATT and at completion was done and biopsy was advised for atypical cases, and those who failed to show clinical improvement after ATT.

\section{RESULTS}

Most common site of involvement was cervical 47 (90.4\%) followed by axillary and inguinal. Out of 52 cases smears revealed epithelioid granuloma with caseation necrosis in 29 cases (55.8\%), while 20 cases (38.5\%) showed epithelioid granuloma without necrosis and 3 cases (5.8\%) showed caseation necrosis without epithelioid granuloma. Out of 52 patients AFB positivity was se en in 22 patients (42.3\%), of which maximum AFB positivity was seen in smears showing caseation necrosis alone without epithelioid granuloma (66.7\%) followed by epithelioid granuloma with caseation necrosis (44.8\%). Smears with epithelioid granuloma alone showed AFB positivity in (35\%) cases.

\section{CONCLUSION}

- Epithelioid granuloma with caseation necrosis was found to be the most common cytological pattern.

- Maximum AFB positivity was seen in cases where necrosis was the predominant microscopic pattern.

- $\quad$ Coupling FNAC with Ziehl-Neelsen staining increases the diagnostic accuracy in tubercular lymphadenopathy.

\section{KEYWORDS}

Tubercular Lymphadenopathy, Ziehl-Neelsen Staining, Acid-Fast Bacilli, FNAC.

HOW TO CITE THIS ARTICLE: James BP, Vithayathil AA. Study of cytological pattern in tubercular lymphadenopathy and its correlation with Ziehl-Neelsen staining. J. Evolution Med. Dent. Sci. 2018;7(07):853-855, DOI: 10.14260/jemds/2018/194

\section{BACKGROUND}

Tuberculosis is one of the leading causes of death due to infectious disease worldwide. Approximately, 8 - 10 million people are infected with this pathogen every year.(1,2) To make the global situation more worse, TB has formed a lethal combination with HIV. In some settings, EPTB can account for upto 53 to 62 percent of cases of TB in HIV-positive individuals.(3-6) Tubercular lymphadenopathy is the most common extrapulmonary manifestation of tuberculosis. In lymph node tuberculosis, cervical region is the most frequently affected site. ${ }^{(7-9)}$

'Financial or Other Competing Interest': None.

Submission 19-12-2017, Peer Review 31-01-2018,

Acceptance 07-02-2018, Published 12-02-2018.

Corresponding Author:

Dr. Ancy Anthony Vithayathil,

Al-Azhar Medical College \& Super Speciality Hospital,

Ezhaloor, Thodupuzha,

Jdukki-685605 (D. T), Kerala.

E-mail:anzav123@yahoo.com

DOI: $10.14260 /$ jemds $/ 2018 / 194$
Clinical examination of patients with tubercular lymphadenopathy of different age groups, sex and social status many a time fails to solve the problem and does not lead to final diagnosis. Hence, we often need the help of a pathologist and a microbiologist to help us to overcome this problem for a correct diagnosis.

The key to control tuberculosis is its rapid detection(10) under rapid diagnostic methods, "fine needle aspiration cytology" is a simple and efficient outpatient procedure employed in the early diagnosis of tuberculous lymphadenopathy.(11) Fine needle aspiration cytology is proved safe, quick, reliable and cost effective procedure. In addition, to helping in the diagnosis of lymph node tuberculosis it avoids physical/psychological trauma, local/general anaesthesia, surgical operations and hospitalisation which are the main problems faced during an excisional biopsy. Hence, this study was done to assess the various cytological patterns in tubercular lymphadenopathy and its correlation with Ziehl-Neelsen staining.(12-14) 


\section{MATERIALS AND METHODS \\ Study Setting}

This is a retrospective descriptive study done in Department of Respiratory Medicine and Department of ENT, Meenakshi Medical College Hospital and Research Institute from September 2011 to September 2013. Total of fifty two patients were evaluated in the study.

\section{Details of the Study}

Fifty two patients referred from various departments, whose fine needle aspiration cytology patterns suggestive of tubercular adenopathy were followed up and those who showed a clinical improvement after a full course of antitubercular treatment were included in the study.

Patients presenting with peripheral lymphadenopathy were subjected to brief clinical examination and information regarding age, gender, anatomical site, chest x-ray findings, Mantoux testing and associated comorbidities like diabetes mellitus and HIV were noted. Their FNAC pattern and ZiehlNeelsen staining results were recorded. Sputum AFB was done in all patients. All the patients cytologically proved as tubercular lymphadenitis were started on anti-tubercular treatment. Follow-up of all patients throughout the course of ATT and at completion was done and biopsy was advised for atypical cases and those who showed a poor response to ATT. Study included new cases of cytologically diagnosed tuberculous lymphadenopathy of all age groups. Previously diagnosed or incompletely treated tuberculous lymphadenopathy cases were excluded.

\section{Statistical Analysis}

Data were analysed using SPSS (Software Statistical Package for the Social Sciences) version 21. Categorical data were expressed in frequency with percentage and association was tested using Chi-square test. A 'p' value of less than 0.05 was considered as statistically significant.

\section{RESULTS}

Fifty two patients referred from various departments whose FNAC patterns were suggestive of tubercular adenopathy and showed a clinical improvement after a full course of antitubercular treatment were included in the study. Their FNAC pattern and Z-N staining were recorded. All the cases were followed up throughout the course of treatment and two cases were subjected to excisional biopsy, which confirmed the cytological diagnosis. Sputum AFB was found to be negative in all the patients.

Fine needle aspiration was done in all 52 patients and the cytological findings were divided into three groups. Most common pattern was epithelioid granuloma with caseation necrosis, seen in 29 patients (55.8\%), followed by epithelioid granuloma without necrosis in 20 patients (38.5\%). Three cases showed caseation necrosis alone without epithelioid granuloma (5.8\%).

\begin{tabular}{|c|c|c|}
\hline Cytological Pattern & No. of Patients & \% \\
\hline Epithelioid granuloma with necrosis & 29 & $55.8 \%$ \\
\hline Epithelioid granuloma & 20 & $38.5 \%$ \\
\hline Necrosis alone & 3 & $5.8 \%$ \\
\hline Total & $\mathbf{5 2}$ & $\mathbf{1 0 0 \%}$ \\
\hline \multicolumn{2}{|c|}{$\begin{array}{c}\text { Tymple 1. Cytological Pattern in Tubercular } \\
\text { Lymadenopathy }\end{array}$} \\
\hline
\end{tabular}

In all the cases one smear was stained with Ziehl-Neelsen technique and examined for the presence of acid-fast bacilli. Out of 52 cases, AFB positivity was found in 22 cases $(42.3 \%)$.

Correlation was done between various cytological patterns and AFB staining. Maximum AFB positivity was seen in smears revealing caseation necrosis without epithelioid granuloma. Out of three cases of necrosis pattern, AFB was positive in two cases (66.7\%) followed by epithelioid granuloma with caseation necrosis showing AFB positivity in 13 cases $(44.8 \%)$. Pattern revealed as epithelioid granuloma alone showed an AFB positivity in 7 cases (35\%).

\begin{tabular}{|c|c|c|c|}
\hline Cytological Pattern & $\begin{array}{c}\text { No. of } \\
\text { Cases (\%) }\end{array}$ & $\begin{array}{c}\text { AFB } \\
\text { Positive } \\
\text { Cases } \\
\end{array}$ & \begin{tabular}{|c|} 
AFB \\
Negative \\
Cases \\
\end{tabular} \\
\hline $\begin{array}{l}\text { Epithelioid granuloma } \\
\text { with caseation necrosis }\end{array}$ & $\begin{array}{c}29 \\
(55.8 \%)\end{array}$ & $13(44.8 \%)$ & $16(55.2 \%)$ \\
\hline $\begin{array}{c}\text { Epithelioid granuloma } \\
\text { alone }\end{array}$ & $20(38.5 \%)$ & $7(35 \%)$ & $13(65 \%)$ \\
\hline Necrosis alone & $3(5.8 \%)$ & $2(66.7 \%)$ & $1(33.3 \%)$ \\
\hline Total & 52 & $22(42.3 \%)$ & $30(57.7 \%)$ \\
\hline 10 & $\begin{array}{l}\text { etwe } \\
\text { FB St }\end{array}$ & ytological & \\
\hline
\end{tabular}

Chi-square test was performed to check the association between cytological pattern and AFB staining. A 'p' value of 0.54 was obtained indicating there was no association between the said variables.

\section{DISCUSSION}

Superficial lymphadenopathy is a very common clinical finding, aetiology of which can be suspected by clinical signs and symptoms. However, a morphological diagnosis is essential to start anti-tubercular treatment in case of tubercular lymphadenopathy. FNAC is a simple, reliable, noninvasive, time conserving and economic technique having practically no complication and has a high patient acceptance. In tubercular lymphadenopathy, FNAC of lymph node has a high sensitivity and can replace excision biopsy in developing countries like India. The sensitivity of FNAC can be further increased by performing a Ziehl-Neelsen staining on the FNAC smears. The aim of this study is to describe various cytological patterns of tubercular lymphadenopathy with their relative frequency and to assess correlation between FNAC and Z-N staining in diagnosing tubercular lymphadenopathy.

In the present study, most common pattern was epithelioid granuloma with caseation necrosis in 29 patients (55.8\%) followed by epithelioid granuloma without necrosis in 20 cases (38.5\%). Three cases showed caseation necrosis alone without epithelioid granuloma (5.8\%). In our study, epithelioid granuloma with necrosis was the predominant cytological pattern which is in accordance with study conducted by Dash SP et al(14) and Handa U et al.(15)

In the present study, out of 52 cases AFB positivity was found in 22 cases (42.3\%). Similar studies showed an AFB positivity of $71.7 \%$ by Ergete and Bekele,(16) $59.4 \%$ cases by Bezabih et al(17) $45.6 \%$ cases by Dasgupta et al(18) and $19.6 \%$ cases by Aggarwal et al.(19)

Maximum AFB positivity was seen in pattern showing caseation necrosis alone without epithelioid granuloma (66.7\%). Smears showing epithelioid granuloma with caseation necrosis showed AFB positivity in 13 cases 
(44.8\%). Epithelioid granuloma alone without caseation necrosis showed AFB positivity in 7 cases (35\%).

AFB positivity was seen in $66.7 \%$ cases, where necrosis was the predominant cytological pattern compared to $44.8 \%$ cases showing epithelioid granuloma with necrosis as the cytological pattern. These findings correlated with other studies as shown in Table No. 21. Thus, a predominantly granulomatous reaction with little or no co-existent necrosis would be associated with the presence of few or no AFB, while a predominantly necrotic reaction would be expected to show AFB positivity. Increasing percentage of AFB is being observed with increase in the caseation necrosis. Conversely with more epithelioid granulomas, the chance of AFB positivity declined (Table 3).

\begin{tabular}{|c|c|c|c|}
\hline Study & $\begin{array}{c}\text { AFB\% in } \\
\text { Epithelioid } \\
\text { Granuloma } \\
\text { with Necrosis }\end{array}$ & $\begin{array}{c}\text { AFB\% in } \\
\text { Epithelioid } \\
\text { Granuloma }\end{array}$ & $\begin{array}{c}\text { AFB\% in } \\
\text { Necrosis } \\
\text { Alone }\end{array}$ \\
\hline Bhardwaj K et al & $31.18 \%$ & $11.53 \%$ & $80 \%$ \\
\hline Dash SP et al(14) & $64.7 \%$ & $9.1 \%$ & $77.4 \%$ \\
\hline Bezabih M et al(17) & $61.9 \%$ & $20 \%$ & $69.7 \%$ \\
\hline Handa U et al(15) & $51.2 \%$ & $18 \%$ & $63.1 \%$ \\
\hline Present Study & $44.8 \%$ & $35 \%$ & $66.7 \%$ \\
\hline Table 3. Comparative Study showing AFB\% in various \\
Cytological Patterns \\
\hline
\end{tabular}

\section{CONCLUSION}

Epithelioid granuloma with caseation necrosis was found to be the most common cytological pattern. Maximum AFB positivity was seen in cases where necrosis was the predominant microscopic pattern. Coupling FNAC with ZiehlNeelsen staining increases the diagnostic accuracy in tubercular lymphadenopathy. In a resource limited setting FNAC coupled with ZN staining for AFB is a very useful tool in the diagnosis of tuberculous lymphadenitis.

\section{REFERENCES}

[1] Raja A. Immunology of tuberculosis. Indian J Med Res 2004;120(4):213-32.

[2] Thompson MM, Underwood MJ, Sayers RD, et al. Peripheral tuberculous lymphadenopathy: a review of 67 cases. Br J Surg 1992;79(8):763-4.

[3] patlymph.pdf [cited 2018 Feb 8]. http://jkscience.org/archive/Volume83/patlymph.pdf

[4] Global Tuberculosis Control: Surveillance, Planning, Financing - WHO - OMS. [cited 2018 Feb 8]. http://apps.who.int/bookorders/anglais/detart1.jsp? codlan $=1 \& \operatorname{cod} c o l=15 \& \operatorname{codcch}=3659$
[5] Lazarus AA, Thilagar B. Tuberculous lymphadenitis. Dis Mon 2007;53(1):10-15.

[6] Sharma M, Agarwal S, Wadhwa N, et al. Spectrum of cytomorphology of tuberculous lymphadenitis and changes during anti-tubercular treatment. Cytopathology 2007;18(3):180-3.

[7] Stelianides S, Belmatoug N, Fantin B. Manifestations and diagnosis of extrapulmonary tuberculosis. Rev Mal Respir 1997;14 Suppl 5:S72-87.

[8] Ohtake $M$, Saito $H$, Okuno $M$, et al. Esophagomediastinal fistula as a complication of tuberculous mediastinal lymphadenitis. Intern Med 1996;35(12):984-6.

[9] Khan AH, Sulaiman SA, Muttalif AR, et al. Tuberculous lymphadenitis at Penang general hospital, Malaysia. Med Princ Pract 2011;20(1):80-4.

[10] M5-m10.pdf. [cited 2018 Feb 8]. http://ntiindia.kar.nic.in/cddistrictlevel/Ielearn/CAT EGORY/RNTCP\%20Modules/M5-m10.pdf

[11] Singh B, Moodley M, Goga AD, et al. Dysphagia secondary to tuberculous lymphadenitis. South Afr J Surg 1996;34(4):197-9.

[12] Organization WH. Global tuberculosis control: WHO report 2011. Geneva: World Health Organization 2011. $\begin{array}{llll}\text { [cited } & 2018 & \text { Feb } & 8\end{array}$ http://www.who.int/iris/handle/10665/44728

[13] Waksman SA. The conquest of Tuberculosis. University of California Press 1964.

[14] Dandapat MC, Mishra BM, Dash SP, et al. Peripheral lymph node tuberculosis: a review of 80 cases. $\mathrm{Br} \mathrm{J}$ Surg 1990;77(8):911-2.

[15] Handa U, Garg S, Mohan H, et al. Role of fine needle aspiration cytology in diagnosis and management of thyroid lesions: a study on 434 patients. J Cytol 2008;25(1):13-17.

[16] Ergete W, Bekele A. Acid fast bacilli in aspiration smears from tuberculous patients. Ethiop J Health Dev 2000;14(1):99-104.

[17] Bezabih M, Mariam DW, Selassie SG. Fine needle aspiration cytology of suspected tuberculous lymphadenitis. Cytopathol 2002;13(5):284-90.

[18] Dasgupta A, Ghosh RN, Poddar AK, et al. Fine needle aspiration cytology of cervical lymphadenopathy with special reference to tuberculosis. J Indian Med Assoc 1994;92(2):44-6.

[19] Aggarwal P, Wali JP, Singh S, et al. A clinicobacteriological study of peripheral tuberculous lymphadenitis. J Assoc Physicians India 2001;49:80812. 